\title{
Use of information technology by adolescents and young people and its effect on health promotion
}

Lucia Maria Lotrean ${ }^{1}$, Roxana Ailoaiei ${ }^{1}$, Ovidiu Stan ${ }^{1,2}$

${ }^{1}$ Iuliu Hatieganu University of Medicine and Pharmacy, Cluj-Napoca, Romania

${ }^{2}$ Technical University, Cluj-Napoca, Romania

Coresponding author

Lucia Lotrean

Cezar Petrescu Str. No. 6, Cluj-Napoca, Romania

E-mail: llotrean@umfcluj.ro

\begin{abstract}
This paper focuses on the effects of the use of information technology by adolescents and young people and its effect on health promotion among them. The data are based on literature review. The threats posed by the use of these technologies include increasing risk for sedentary behavior in combination with inappropriate alimentary habits, risk for bulling, risk of exposure to advertisement for tobacco and alcohol products. On the other hand, information technologies have the potential to help and boost the implementation of effective, accessible and sustainable health education programs, but there are several research questions and challenges which should be addressed, such as a. type of theoretical concepts, educational strategies and materials which stimulates self-directed, curiosity-based learning and development of skills and increase confidence for adopting healthy lifestyle b. finding ways to improve teachers' skills or formal education they need to empower learners to pursue their own interests and free class time for more experiential forms of learning c. understanding how social media can be used for healthy lifestyle promotion and how to avoid missteps is very important $\mathrm{d}$. the challenge to enable pupils to work in collaboration with classmates and teachers to create environments which stimulates education for healthy lifestyle promotion. e. creating authentic learning environment stimulated through games, discussions, and group tasks. In the present, in Romania it is under development an educational program for healthy lifestyle promotion for pupils with hearing disabilities using communication networks, information technology and media.
\end{abstract}

Key words: Information technology; health promotion; young people 


\section{Introduction}

Adolescents use and interact with media in different ways. Watching television remains still the most frequent ways for watching media, but new emerging technologies lead in several countries to an increasing trend of watching media on other devices such as computers, tablets, mobile phones[1] . Adolescents use different forms of information and communication technologies to get different information, to play games, to perform homework, to send messages, to network with other peers. Use of internet, social media as well as sending messages from mobile phones are increasing very much in several countries of Europe, including Romania [2,3,4]

The use of information and communication technology by adolescents and young people can pose both threats and opportunities for their health. Hence, this study focuses on the effects of the use of information technology by adolescents and young people on health promotion, giving a special attention to the context and challenges from Romania. The data are based on literature review.

\section{Use of information and communication technologies by adolescents and young people-threats for health promotion}

There are several threats for health posed by excessive use of information technologies. These include the following:

1. Effects on physical activity, sedentary behavior, alimentary behavior

Different studies show that increased media use is associated with decreasing of involvement in physical activity. Additionally, those who watch more TV than the average adolescent tend to have poorer dietsconsuming more calories or higher-fat diets, drinking more sodas, and eating fewer fruits and vegetables. At the same time, watching TV is not only increasing sedentary behavior, but can interfere with sleep duration and quality[1,4,5] .

Recently, different studies have assessed the effects of new information and communication technologies on physical activity, but the results are mixed. Some studies show that they increase the number of hours of sedentary behavior and decrease the number of hours of physical activity, while others presented results which show that he use of these technologies increases the involvement in physical activity[4-7] .

A study performed in Hungary assessed on the basis of two cross-sectional surveys, the changes occurred within eight years in the free-time activity of Hungarian young people aged between 15 and 19 years. Data were obtained from two surveys conducted by the National Institute for Family and Social Policy, Hungary in 2000 and 2008 including 1780 and 2018 young people. The results show an increase in the number of young people regularly involved in sport activity, while their media-consumption did not decrease. Use of computers did not increase sedentary lifestyle and deviant habits, while internet use had positive effects on the regularity of their physical activity[6] .

A cross-sectional study was performed among 2,083 adolescents (11-17 years) from all over Germany between 2009 and 2012 in the Motorik-Modul Study. The results of this study show that very high media use occurred with low physical activity behavior, but very high activity levels co-occurred with considerable amounts of time using any media. There was no evidence that type of used media was related to physical activity levels; setting of physical activity was not related to amount of media use in any pattern[5] .

The use of cell phones increase opportunities for activities traditionally defined as sedentary behaviors such as surfing the internet or playing video games, but since these devices are portable, cell phone use might not be a sedentary behavior. Nevertheless, a study performed among college students from United States of America shows that cell phone use, like traditional sedentary behaviors, may disrupt physical activity and reduce cardiorespiratory fitness[7] . 


\section{Bullying}

Bullying involvement in any form can have lasting physical and emotional consequences for adolescents and a big concern is raised by the risks of cyberbullying which might take the place or come together with the traditional bullying[8,9] . A growing body of literature has begun to document the prevalence, predictors, and outcomes of this behavior ${ }^{9}$. A review of 80 studies that reported corresponding prevalence rates for cyber and traditional bullying and/or aggression in adolescents showed that traditional bullying was twice as common as cyber bullying. Cyber and traditional bullying were also highly correlated, suggesting that polyaggression involvement should be a primary target for interventions and policy[8]

There are several effects of social media on how adolescents and young people interact, cyberbullyingy emerging as a potential harm. A review examined existing publications that focused on the health-related effects of cyberbullying via social media among adolescents. Thirty-six studies in 34 publications were included. Most were conducted in the United States and included adolescents who were 12 to 18 years of age. The median reported prevalence of cyberbullying was $23.0 \%$. Five studies reported inconsistent and/or weak correlations between cyberbullying and anxiety. Ten studies found a statistically significant association between cyberbullying and report of depression. Five studies investigated selfharm or suicidality, with conflicting results. The results indicate that the prevalence of being bullied via social media was more frequent among girls, the most common reason for cyberbullying being relationship issues. The results also underline that the responses to cyberbullying are most often passive, due to lack of awareness or confidence that anything can be done[10] .

3. Exposure to tobacco and alcohol advertisement

Exposure to tobacco and alcohol advertisement is associated with smoking initiation among the youth and stimulates alcohol consumption. Historically, the tobacco industry has pioneered the use of media to promote their products. Nowadays, with increasing restrictions on smoking advertisement on television, newspapers, billboards, they are moving to use the new information and communication technologies for promoting their products. Internet and video games are becoming significant media for massive communication and providing new opportunities for advertisement for tobacco and alcohol products as well as electronic cigarettes[11] .

\section{Use of information and communication technologies by adolescents and young people -opportunities for health promotion}

The information and communication technologies can play an important role in health education and health promotion, such as[2,4,12]:

1. Informing participants about the possibilities to participate in different activities/programs through e-mail, social media, web page

2. Facilitating communications between participants and organizing institutions involved in health promotion

3. Web pages with information, educational materials, games, which promote healthy lifestyle

4. Use of computer tailored programs which allows the development of individualized education and counseling for health promotion

Information technologies have the potential to help and boost the implementation of effective, accessible and sustainable health education programs, but there are several research questions and challenges which should be addressed, such as[2-4,11-14] :

a. type of theoretical concepts, educational strategies and materials which stimulates selfdirected, curiosity-based learning and development of skills and increase confidence for adopting healthy lifestyle

b. finding ways to improve teachers' skills or formal education they need to empower learners to pursue their own interests and free 
class time for more experiential forms of learning

c. understanding how social media can be used for healthy lifestyle promotion and how to avoid missteps is very important

$\mathrm{d}$. the challenge to enable pupils to work in collaboration with classmates and teachers to create environments which stimulates education for healthy lifestyle promotion.

e. Creating authentic learning environment stimulated through games, discussions, and group tasks.

In the present, in Romania it is under development an educational program for healthy lifestyle promotion for pupils with hearing disabilities using communication networks, information technology and media. The main goal of this project is healthy lifestyle promotion among children with hearing disabilities from Romania.The project focuses on smoking prevention, promotion of healthy nutrition and active lifestyle. It targets pupils from the grade I-VIII from 2 schools deserving children with hearing deficiences, their parents and school staff of these schools. The project includes the creation of comunication networks for parents and school staff regarding healthy lifestyle promotion among children with hearing disabilities. Moreover, school based and out of school educational activities for healthy lifestyle promotion are implemented among pupils using different forms of media and information technology.

\section{Conclusions}

The use of different forms of information technologies is increasing and it is particular popular among adolescents and young people. It can have bad consequences, but these might be reduced by good communication between parents and children as well as supervision from parents of what children are doing regarding mobile phones use, texting, internet and social media use ${ }^{1}$.

On the other hand, the information and communication technologies have a big potential in helping health education and health promotion, which raise a big opportunity for health professionals and educators in developing, implementing, evaluating and disseminating appropriate health education programs.

\section{Acknowledgments}

This work was supported by a grant of the Romanian National Authority for Scientific Research and Innovation, CNCS UEFISCDI, project number PN-II-RU-TE2014-4-2631.

\section{References}

1. American Academy of Pediatrics. (2011). Policy statement--Children, adolescents, obesity, and the media. Pediatrics, 128: 201208.

2. Lotrean LM, Mocean F, Laza V. (2009). The role of information technology in health education: strengths and weaknesses. Proceedings of the International Conference on Advancements of Medicine and Health Care through Technology 23-26 September, 2009, Cluj-Napoca, Romania Springer Berlin Heidelberg, 72-76.

3. European Comission (2014). The NMC Horizon report Europe: 2014 Schools Edition. Luxemburg, The New Media Consortium.

4. Lotrean LM, Lupsa T, Olivo del Valle M, Stan O, Lencu C. (2016). The use of internet and its relationship with the involvement in physical activity among Romanian school children from urban and rural areas. Palestrica Mileniului III, 17: 9-13.

5. Spengler S, Mess F, Woll A. (2015) Do Media Use and Physical Activity Compete in Adolescents? Results of the MoMo Study. PLoS One, 10(12): e0142544.

6. Takács B. (2013). Changes in leisure activity among young people aged 15-18 years in Hungary: physical activity, mediaconsumption and smoking. Orvosi Hetilap, 154: 581-9.

7. Lepp A, Barkley JE, Sanders GJ, Rebold M, Gates P. (2013). The relationship between cell phone use, physical and sedentary activity, and cardiorespiratory fitness in a sample of U.S. college students. International Journal of Behavioral Nutrition and Physical Activity, 10:79.

8. Modecki KL, Minchin J, Harbaugh AG, Guerra NG, Runions KC. (2014). Bullying 
prevalence across contexts: a meta-analysis measuring cyber and traditional bullying. Journal of Adolescent Health, 55: 602-11.

9. Carter JM, Wilson FL. Kowalski RM, Giumetti GW, Schroeder AN, Lattanner MR (2015). Cyberbullying: a 21st Century Health Care Phenomenon. Pediatric Nursing, 41:11525.

10. Kowalski RM, Giumetti GW, Schroeder AN, Lattanner MR. (2014). Bullying in the digital age: a critical review and meta-analysis of cyberbullying research among youth. Psychollogical Bulletin, 140:1073-137.

11. Barrientos-Gutiérrez T, Barrientos-Gutiérrez I, Reynales-Shigematsu LM, Thrasher JF, Lazcano-Ponce E. (2012). Aiming for the adolescent market: internet and video games, the new strategies of the tobacco industry. Salud Publica de Mexico, 54:303-14.

12. Rimer BK, Kreuter MW. (2006). Advancing tailored health communication: a persuasion and message effects perspective. Journal of Communication, 56:184-201.

13. Hawkins RP, Kreuter M, Resnicow K, Fishbein M, Dijkstra A. (2008). Understanding tailoring in communicating about health. Health Education Research, 23:454-66.

14. Shegog R, McAlister AL, Hu S, Ford KC, Meshack AF, Peters RJ. (2005). Use of interactive health communication to affect smoking intentions in middle school students: A pilot test of the "Headbutt" Risk assessment program. American Journal of Health Promotion, 19:334-8. 